\title{
The Social Tools of Web 2.0: Opportunities for Academic Libraries
}

\author{
By EllysSa Kroski
}

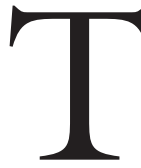

he world of the Web has changed as a new breed of software applications makes it easy to accomplish incredibly sophisticated tasks with little technical know-how. The Internet has seen an explosion of social tools that are empowering ordinary people to connect and participate in a global conversation. People who had previously accessed the Web solely for shopping or research purposes now sign on for the experience of creating and sharing information in the public sphere. They are crafting both content and connections with other users in a new Web that links people to people, as well as to information.

Web 2.0 is loosely defined as the evolution to a social and interactive Web that gives everyone a chance to participate- not just those with programming skills. By producing new applications that are simple to use, Web 2.0 breaks down the technological barriers to entry and, in essence, democratizes the Internet.

The social tools of Web 2.0 are some of the hottest properties on the Internet now. The teen social ecosystem $M y S$ pace is frequented by over 130 million members, while YouTube's video-sharing

Ellyssa Kroski is a Reference Librarian for Columbia University as well as an independent Information Consultant, national conference speaker, and adjunct faculty for Long Island University's LIS program. She is currently writing a book titled Web 2.0 for Librarians and Information Professionals for Neal-Schuman Publishers. She authors the blog InfoTangle at http://infotangle.blogsome.com. She may be contacted at ellyssakroski@yahoo.com. community is the fifth-highest-trafficked Web site in the world. Over 250 million photos have been uploaded by amateur shutterbugs to Flickr, and Wikipedia's contributors have authored 4 million articles. These online haunts have become neighborhood hangouts, where people convene to chat and express themselves. They provide a social space beyond work and home, where people go seeking a community experience. In so doing they have helped transform the Web into a true "third place." 1

In their day-to-day lives, people are initiating incredible exchanges of knowledge through new Web tools that enable them to create, collaborate, socialize, and share with their family, friends, colleagues, classmates, and acquaintances. Web novices are creating knowledge repositories on wikis, developing bibliographies through social bookmarking sites, building historical and cultural collections through media sharing applications, and forming relationships with like-minded individuals in social networking communities. Today's Internet audience has evolved to become a culture of creators.

The Web 2.0 networks that enable people to create and contribute original content, such as photos, reviews, bookmarks, tags, and videos, simultaneously offer users valuable information collections built by the populace. By leveraging their communities in this way, they aggregate the knowledge of their individual members and form discovery systems that people can explore via human pathways. Web users today are negotiating these social Web sites in order to gather information, discover the unexpected, and experience the authentic creations of their peers. This DIY (do-ityourself) model of information consump- tion captures the spirit of the new Web and places the reins of control firmly in the hands of users.

Community is the new nexus for information; therefore, these online social spots are exactly where libraries will want to be. Through social networks, librarians have the opportunity to connect with patrons in ways that were never possible in the past, by offering services to users in their own space. Now more than ever, libraries can reach users where they live.

This essay explores the social tools of Web 2.0 and their potential uses within academic libraries. Four genres of social tools are discussed in four main sections: Content Collaboration (wikis and online office applications), Social Bookmarking, Media Sharing, and Social Networking. For each type of social tool, the genre is first described, frequently with examples. A discussion of popular software applications follows. The tool is then discussed in relation to potential and actual use in academic libraries. Tools and sites, indicated in the text in italics, are listed alphabetically within the four main sections of the Links Cited list following the conclusion of the essay. Unless otherwise noted, all software resources mentioned are available in a basic form for free, although some do charge for additional functionality.

\section{Content Collaboration}

Knowledge sharing among distributed group members was a daunting task before the emergence of new Web 2.0 tools. Cooperation and participation, cornerstones of the new Web, are personified in content collaboration tools, which provide an online space for information sharing and cre- 
ation within a community. Software such as wikis and online office applications enable groups to ignore the constraints of time and location and simply achieve their goals.

\section{Wikis}

A wiki is a collaborative online tool that enables a community of contributors to work together to create Web sites and documents quickly and easily. The term "wiki" comes from the Hawaiian, meaning quick or fast. Wiki software offers users a speedy Web publishing medium that does not require knowledge of HTML. Wikis can be used by team members to brainstorm ideas, gather specialized knowledge, serve as a teaching resource, and replace intranets. They can be made open to the public, limited to a private community, or a combination of both; they can be created for outreach or used solely within the enterprise.

Written in over 200 languages, Wikipedia: The Free Encyclopedia has harnessed its community's collective intelligence to create the largest and most renowned wiki in the world. This encyclopedia is open to the public to both create and consult. It enjoys a community of over 100,000 global contributors who have furnished 4 million entries on subjects as diverse as computer software, poetry, and horticulture.

Wikis allow group members to create and edit pages with a click of a button, often providing a WYSIWYG (What You See Is What You Get) interface, similar to word processing applications. Editors can create

\section{Web 1.0 Content Collaboration}

Word documents used to be e-mailed back and forth among a group of users, each of whom could accept or reject changes. Edits were tracked and appeared underlined in red with user comments appearing in callout boxes. Team members would need to wait while each contributing author received and edited the file and then forwarded it on to the next member. content, using toolbars for adding links, customizing text, and inserting images. Any team member can create a new page, edit an existing page, leave comments on a particular page, delete a page, or revert back to a previous page version.

Wikis employ a unique feature called version control, which allows contributors to view all previous edits and revisions of a wiki page, and enables the option of reverting back to any former version. This is extremely useful in a collaborative environment where one person's erroneous edits could set back the progress of a project, or the graffiti of a malicious user on a public wiki could overwrite essential information. Community editors can keep track of changes made on the wiki by viewing recent changes, or by subscribing to RSS feeds that are available with many wiki programs.

Wikis may grow to become massive repositories of information and knowledge. Although they do not have a preset form of navigation for browsing, one can be created by wiki authors. Another way readers may traverse these resources is through the "show all pages" option available with many wikis, which provides a listing of every page created. Readers may also query by means of the wiki keyword search for quick access to desired information.

Most wikis enable users to upload files and attachments such as Word documents, images, PDF files, and spreadsheets, making them worthy hosts for organizational knowledge bases. In addition to storing

\section{Web 2.0 Content Collaboration}

With new Web 2.0 content collaboration tools such as wikis and Internet office applications, a group of users can work on a document simultaneously and access it from any Web browser. Previous versions can be viewed and compared side-by-side, and authors can revert back to previous iterations of a document by merely clicking a button. documents, many wikis will import documents from Microsoft Word and convert them into wiki pages.

Wikis are similar to blogs, which were discussed in detail by Laura B.Cohen in Choice in August 2006², but there are some important differences. Both are content management systems capable of producing valuable information resources. However, blogs are chronological, meaning that their information is posted and organized according to the date of creation. Wikis, on the other hand, are iterativerecent versions overwrite previous iterations, producing a constantly evolving resource. Blogs have a predefined organizational structure consisting of posts that are arranged in reverse chronological order and then archived according to month. Conversely, wikis develop and organize themselves naturally, according to the needs of their community. Lastly, wikis are most often a community creation, with group members contributing to create a resource. Blogs have traditionally been an individual enterprise.

\section{Online Office Applications}

Online office applications, such as Google Docs es Spreadsheets and Zoho Office Suite, are changing the way people think about productivity solutions. These new collaborative tools provide much of the functionality of Microsoft Office programs without burdening the user with superfluous features, and they are available online. These services enable document creators to share their work with invited collaborators and publish documents to the Web. They enjoy the same version control capability as wikis do, as well as editing freedom among contributors. Through these powerful services, authors can create and share word-processed documents, spreadsheets, and even slideshow presentations.

\section{Content Collaboration Software}

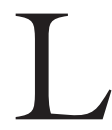
ike blogging software, there are two main types of wiki applications: those that are hosted by the wiki creator, and those that are host- 


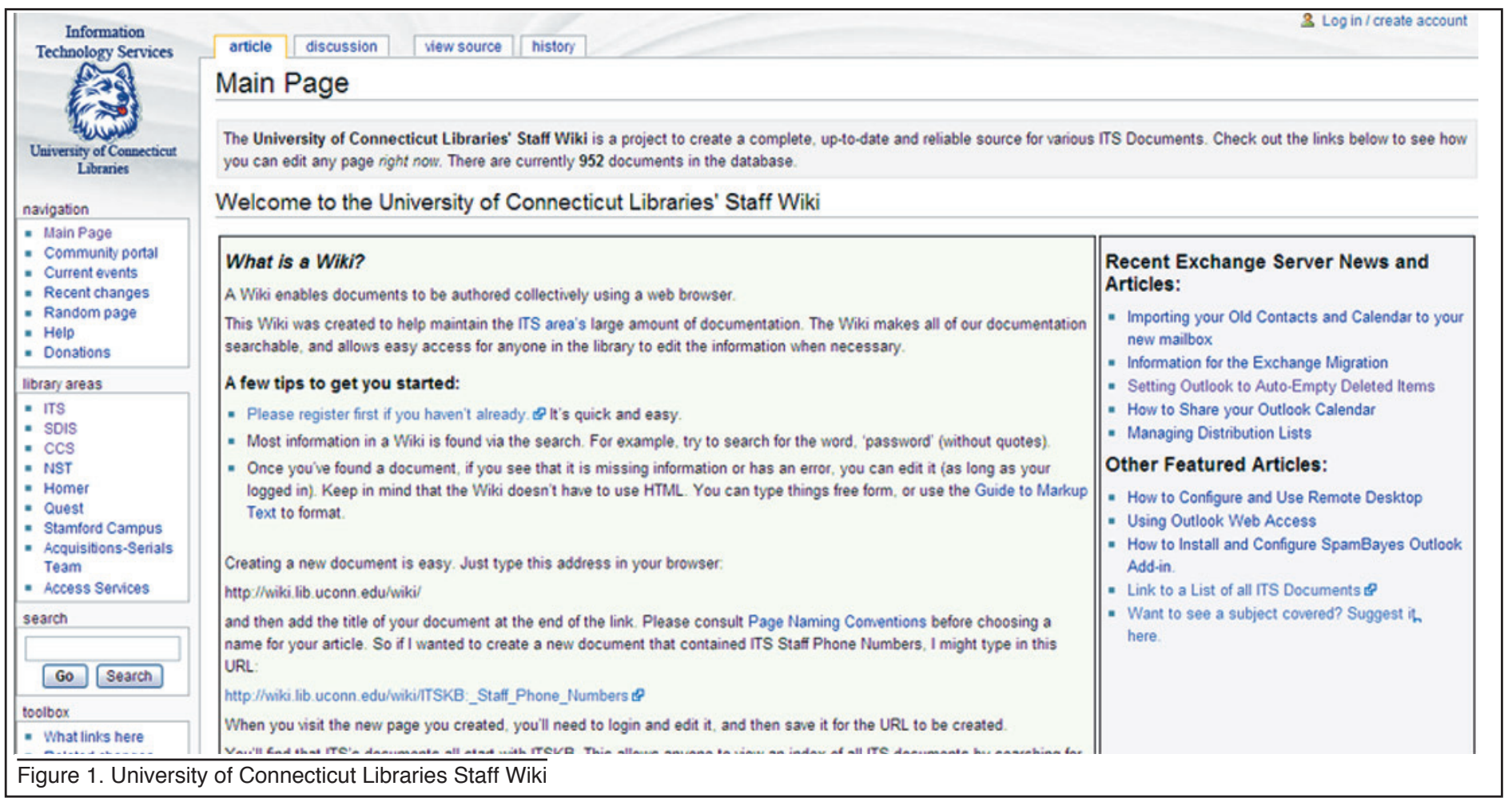

ed and maintained by a service provider. The latter type is often referred to as a wiki farm. Wiki farms are fast and easy solutions for establishing a wiki, while wikis that are self-hosted offer more control, expanded functionality, and additional features.

With over 100,000 wikis created by its community of users, the largest consumer wiki farm to date is $P B W i k i$, which claims that wikis using its software can be created as quickly and easily as making a peanut butter sandwich. PBWiki offers free basic public or private wikis that can be upgraded for a monthly subscription rate. PBWiki provides the standard feature set along with RSS feeds, and the option to back up wikis in ZIP and PDF formats.

Purchased by Google in 2006, JotSpot is another free, hosted wiki alternative aimed at the business sector. Wiki authors can easily create intranet environments with the array of tools provided, including shared calendars, spreadsheets, documents, photo galleries, and blogs. In addition, wiki editors are able to email comments straight to the wiki and import Word documents as wiki pages.
MediaWiki, the wiki program used to create the Wikipedia, is a free, open-source software package licensed under the GNU <http://www.gnu.org/gnu/gnu-history. html> General Public License (GPL). It is a program that must be downloaded and hosted by the wiki creator, and it offers an assortment of extensions that provide greater functionality, such as Google Maps, Quicktime, and YouTube integration.

Silicon Valley's own Socialtext Enterprise Wiki is the most popular wiki software program among corporations-over 2,000 businesses and organizations use the application. Socialtext provides both hosted and nonhosted solutions, as well as a downloadable open-source version of the software. It offers advanced access control and security features, as well as tagging and the ability to e-mail wiki pages out to contacts.

Google Docs \& Spreadsheets, formerly known as Writely, allows authors to create an unlimited number of word-processing documents and spreadsheets and share them with contributors whom they invite. In addition to the standard features offered with such services, Google Docs \& Spreadsheets allows tagging and archiving of documents, as well as importing and exporting in a number of formats.

The Zoho Office Suite, from independent startup AdventNet, offers a portfolio of productivity tools including an online word processor, spreadsheet program, slideshow creator, wiki, database builder, and project management software. Also available: a plug-in for Microsoft Office to edit documents both online and offline, and an open API for widget creation.

ThinkFree offers ThinkFree Online Office tools for creating documents, spreadsheets, and slideshow presentations. The core feature set is available without charge, as well as document tagging capability and exporting documents to blogs.

\section{Content Collaboration and Academic Libraries}

With their quick-start time frame, low learning curve, and facility for outreach, content collaboration tools have many potential uses within academic libraries. Already these useful applications are being implemented within library settings for an array of purposes. 


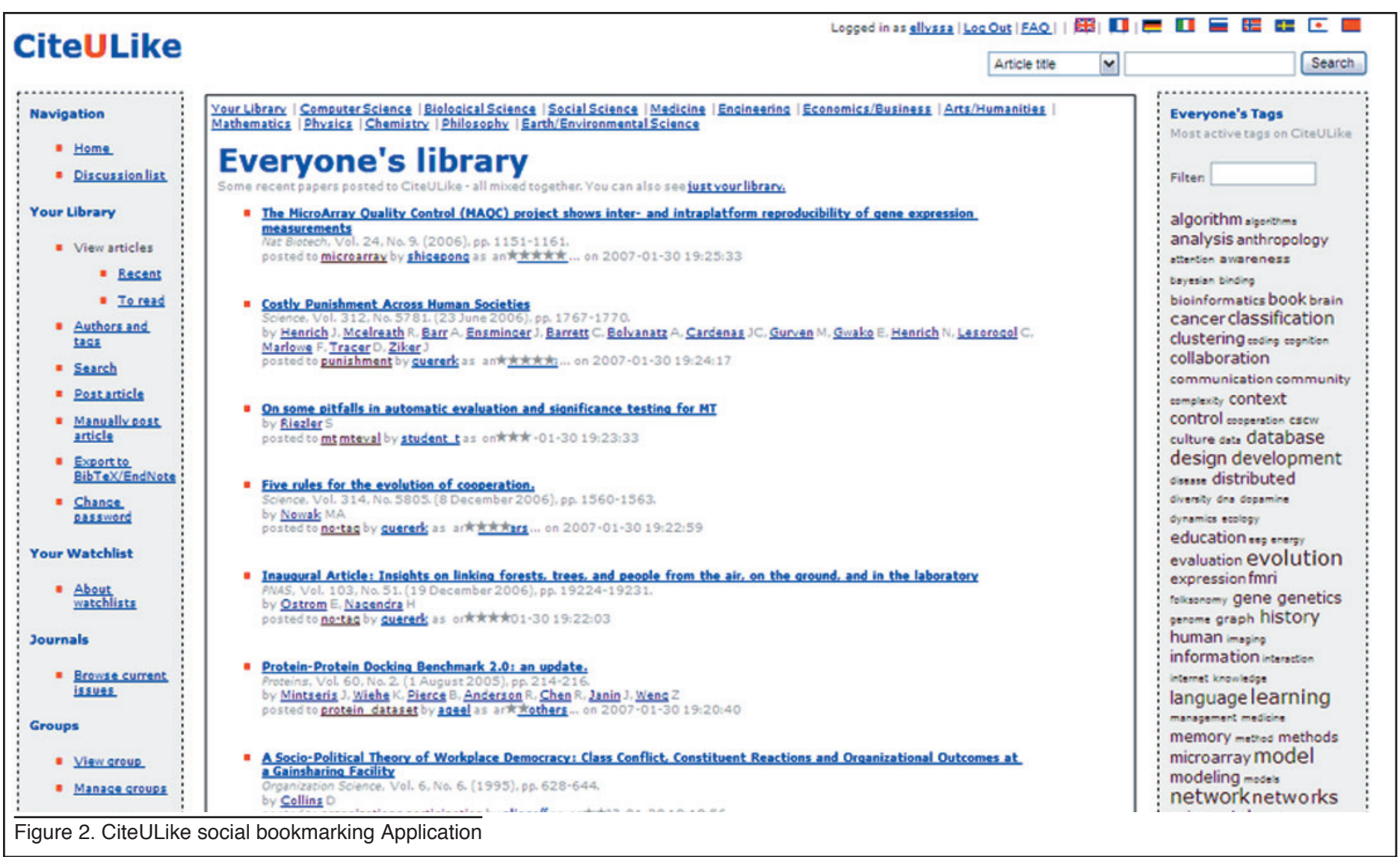

\section{Intranets}

Wikis offer the ability to capture individual expertise into a centralized repository of organizational knowledge, providing a fitting tool for an intranet or knowledge base. The University of Connecticut Libraries' Staff Wiki contains over 950 documents and includes pictures, instructions for printing out time cards, phone trees, and schedules. Anyone employed by the libraries can edit the resource; although the wiki is available to the public, some pages have restricted access.

\section{Training Tools}

Wikis provide a dependable tool for maintaining a pool of departmental knowledge. The Antioch University New England Library Staff Training and Support Wiki documents library opening and closing procedures, instructions for using the ILS, and book processing information.

\section{Library Web Sited}

Because wikis are capable of sustaining many hundreds of pages of information that can be published online without any programming knowledge, they are a natural choice for creating public Web sites such as USC Aiken Gregg-Graniteville Library. Containing research guides, forms, database tips and instructions, as well as links to the OPAC, this wiki has been tailored to create a robust Web site for the University of South Carolina library.

\section{Event Planning Resources}

Since wikis are collaborative devices that encourage group input, they are perfect choices to plan events within a group. Twice a year the American Library Association (ALA) hosts conference-planning wikis for its midwinter and annual conference events. Attendees and exhibitors can plan get-togethers; obtain local information about hotels, restaurants, and tourist attractions; post their personal schedules; and link to photos and external resources. The Official Wiki of the 2007 ALA Annual Conference in Washington, $D C$ is the most recent edition.

\section{Subject Guides}

An ideal means for gathering subject expertise from distributed staff members, wikis can provide a pathfinding tool, pointing to the library's best resources within a particular subject area. The Ohio University Libraries have combined marketing, general, and international business subject guides to create $B i z W i k i$, a searchable and easily updatable resource for patrons. In addition to information about business databases and resources, $B i z$ Wiki provides readers with instructional articles, including how to research companies, and guides to various industries.

\section{Shared Documents}

The Mesquite ISD Library Advisory Committee is revising its current mission 
statement, using its libadvisorywiki to allow staff members to share their thoughts and opinions in a common space. Because both wikis and online office applications provide environments in which many users can quickly and easily edit and share, they are exceptional tools for collective brainstorming, as well as for refining ideas.

\section{Social Bookmarking}

S ocial bookmarking applications enable people to save or bookmark their favorite Web sites, blog posts, images, articles, or podcasts in an online space. By storing bookmarks within communities such as del.icio.us, or StumbleUpon, rather than on the desktop, they can be accessed in the future from any Web-enabled computer. Many people accumulate lengthy lists of bookmarked resources that are made searchable by aggregating them within a social bookmarking Web site. In addition to being an organizational tool used for managing bookmark collections, these Web sites are also discovery systems in which everyone's favorites are open to public perusal. Members may browse community bookmarks to encounter unexpected resources as well as like-minded people.

Social bookmarking Web sites provide browser buttons, called "bookmarklets," which are easily installed and facilitate adding new favorites with the ease of a click. As members browse the Web, they may bookmark new resources by tapping the bookmarklet button. The applications automatically acquire the Web site URL and page name for the resource and move them into an editable form with spaces for members to add notes and keywords. Hyperlinked bookmarks are displayed in list format, along with the number of other users who have "favorited" the item, member notes, and member-assigned "tags," as descriptive keywords are called in Web 2.0 applications.

Social bookmarks may be categorized and classified by tags. Members have the option to add any number of tags to their bookmarks to make them findable in the future. When users bookmark new resources, popular tags are often recommended by the software, based on how others chose to describe the entry. As tags are added, individual members develop personalized taxonomies that help them navigate through their collections.

Social bookmarking communities aggregate the tags used by their individual members, a naturally forming "folksonomy" born of a community's tagging efforts. Members can explore these labyrinthine networks by clicking on tags, the most popular of which are displayed in a "tag cloud." A textual representation of the culture and disposition of a community, as well as an alternative form of navigation, the tag cloud presents the most popular tags in use at a particular time. Tags that are more popular than others are displayed in larger and bolder fonts.

In addition to exploration by tag, members can traverse these Web sites by browsing other users. Most of these applications offer hyperlinked lists of all members who bookmarked particular resources, as well as how they tagged them. This gives insight into classification strategies, and also provides access to the bookmark collections of those with potentially shared interests. When members find either tags or other users they are interested in, they may choose to keep updated by subscribing to them via RSS feeds.

\section{Social Bookmarking Software}

With over one million registered users, del.icio.us is one of the most recognized so-

\section{Web 1.0 Bookmarking}

Web users were able to save or bookmark their favorites within a particular browser, such as Internet Explorer or Firefox, on a single desktop. The only form of organization offered was to group favorites by folders with descriptive names. Bookmarks were not accessible across browser types. cial bookmarking applications on the Web today. It was acquired by the Yahoo! network in December 2005. The Web site offers the usual set of social bookmarking features, but members may also subscribe to other members and tags within the program. Del.icio.us users may bookmark resources for other members and create a friends network. Tags in del.icio.us can be organized into hierarchical bundles.

Stumble Upon utilizes a browser plug-in to enable members to discover new and random resources as they browse the Web. Its 1.2 million members are able to rate and review the Web sites they come across, receive personalized recommendations, and create user groups.

Connotea is a social bookmarking Web site from the publishers of Nature journal. It is aimed at a scientific audience, and automatically acquires citation information for journal articles from supported databases such as PubMed, Blackwell Synergy, and BioMed Central. Members can create public or private libraries of resources that can be imported and exported between Connotea and desktop reference managers.

Cite ULike is a scholarly bookmarking tool that enables members to create detailed bibliographic records for journal articles, dissertations, reports, chapters, and other online sources. The CiteULike service automatically retrieves citation details for articles from a long list of supported databases, including JStor, Ingenta, ProjectMUSE, and Wiley Interscience. Members can export to BibTeX and Endnote, set up watchlists, and create user groups.

\section{Web 2.0 Bookmarking}

Web 2.0 social bookmarking tools allow Internet users to save their bookmarks online where they can be accessed remotely from any Web-enabled computer. Bookmarkers can organize their favorites by utilizing descriptive keywords, allowing them to fall into multiple categories. Additionally, as bookmarkers save their favorites in the public sphere, they are creating resource repositories that can be browsed and discovered by others. 


\section{Social Bookmarking and Academic Libraries}

Due to their ability to assemble large lists of Web-based resources which can be organized according to user preferences, social bookmarking tools are able to offer a wide array of uses within the academic realm. Libraries and librarians are already testing the possibilities with these new social tools.

\section{Class Reading Lists}

With the potential to link to text, video, audio, and image files, social bookmarking Web sites are ideal tools for creating reading lists comprising online resources. Michael Stephens at the Graduate School of Library and Information Science at Dominican University has created a reading list for his LIS753 class using del.icio.us by simply tagging all related resources with the descriptor $l i s 753$.

\section{Subject Guides}

The San Mateo Library has classified all its bookmarked electronic resources according to the Dewey Decimal System, to develop subject guides on del.icio.us. Because of the flexibility of tagging, these applications present great potential for use as dynamic, easy-to-update, electronic resource guides.

\section{Keeping Current}

Members of the library profession keep informed of new developments in the field by browsing bookmarking networks by tags such as library and library 2.0 to find the most recent publications, reports, podcasts, and more. They are staying abreast of new images, presentations, and reviews being posted concerning conferences by searching for tags such as: il2006 (Internet Librarian 2006), and ala2007 (ALA Annual Conference 2007).

\section{Bibliographies}

Academic librarians are developing bibliographies of journal articles and scholarly papers on CiteULike and other academ- ic bookmarking communities where they can record full citation information for each entry and export their libraries to BibTeX or Endnote. These Web sites are valuable tools through which members can easily create bibliographies of online resources and share them with others.

\section{Patron Bookmarking}

The librarians of the University of Pennsylvania have developed a customized social bookmarking system called PennTags. It is a private bookmarking community, made available only to UPenn faculty, staff, and students. Similar to other social bookmarking services, PennTags enables its members to bookmark and tag online resources including records from the library OPAC.

\section{Media Sharing}

W eb 2.0 media sharing Web sites such as YouTube and Flickr enable millions of people to organize and share their photo and video collections online. Amateurs and professionals alike are uploading and broadcasting their creations to the world, as well as rating, reviewing, and bookmarking those of others. Through these massive multimedia communities, members are viewing portraits of indigenous peoples, uploading seascapes and still life studies, creating karaoke clips, anchoring talk shows, and directing low-budget sitcoms-all with little technical difficulty.

\section{Web 1.0 Media Sharing}

Sharing photographs with family and friends used to involve scanning in images, storing them on a hard drive, and e-mailing them to recipients whose mail servers would stagger from the file sizes, or reject them altogether.

Video sharing was not easily accomplished, and was generally undertaken only by those who shared ftp servers, or utilized early peer-to-peer file sharing programs.
Media sharing applications enable members to upload their creations in a variety of file formats that are automatically converted for them. Members can organize and make their collections findable by assigning tags to each item. "Profile" or "channel" pages aggregate and showcase the work of individual members and provide an opportunity to establish a brand presence for those interested in self-promotion.

While all of these substantial collections are searchable, the optimal method of experiencing them is to browse by the "top" or most popular items or tags. While members browse the handiwork of the community, they can save items to their favorites, leave comments on photos and video clips, rate media, and join groups.

\section{Media Sharing Software}

Purchased in 2006 by Google for $\$ 1.65$ billion in stock, YouTube is the world's largest video sharing application, with over 34 million visitors per month. Well over 65,000 new video clips are uploaded every day to this booming community, and over 100 million video clips are served each day to avid viewers. YouTube provides an established set of features for users and also offers playlists, groups, and friends.

Offering much the same functionality as YouTube, Yahoo! Video enables members to upload, share, rate, review, and comment

\section{Web 2.0 Media Sharing}

New Web 2.0 tools make it easier to share media such as photos and videos online than in the real world. Creators need only upload their digital files to media hosts for storage, and then delete them from the desktop. Friends and contacts can access video and image collections through member profiles, and they can subscribe to receive updates about new additions. Photos and videos can now be shared through blog posts, Web sites, e-mail, and IM by pointing to the URL where they are stored. 
on video clips. Videos can be saved and shared via IM (instant messaging) and email. Searches will return video results from across the Web.

Metacafe, a unique Israeli startup, offers its video sharing community cash rewards for quality clips. The site's 24 million visitors view over 400 million videos per month. Metacafe provides the usual set of features as well as the ability to download videos for offline viewing.

One of two Yahoo! photo sharing communities, Flickr has over 2.5 million registered members, has amassed over 250 million digital photos, and adds a million images daily to the collective photostream. Flickr offer more social features than any other application in this space, including tagging, groups, RSS feeds, and options to annotate photos, map images by adding geotags, and apply creative commons licenses.

Over half the traffic to photo-sharing Web site Photobucket originates on MySpace. Photobucket claims over 41 million members who can create slideshows for their profiles on social networking sites such as Facebook and MySpace. Members can also link to their images in instant messengers and e-mails.

\section{Media Sharing and Academic Libraries}

Photos and videos emanate personality and can add a human dimension to an otherwise impersonal organization. Media sharing tools enable libraries to communicate with their patrons in ways that text alone cannot, allowing them to teach lessons, market services, provide resources, and bring their brand to life.

\section{Historical Collections}

Photo sharing Web sites offer the opportunity to create and exhibit historical collections to a very large audience. Colorado College has uploaded Historical Photos of Tutt and Coburn Libraries, its special collection of photographs of the college li-

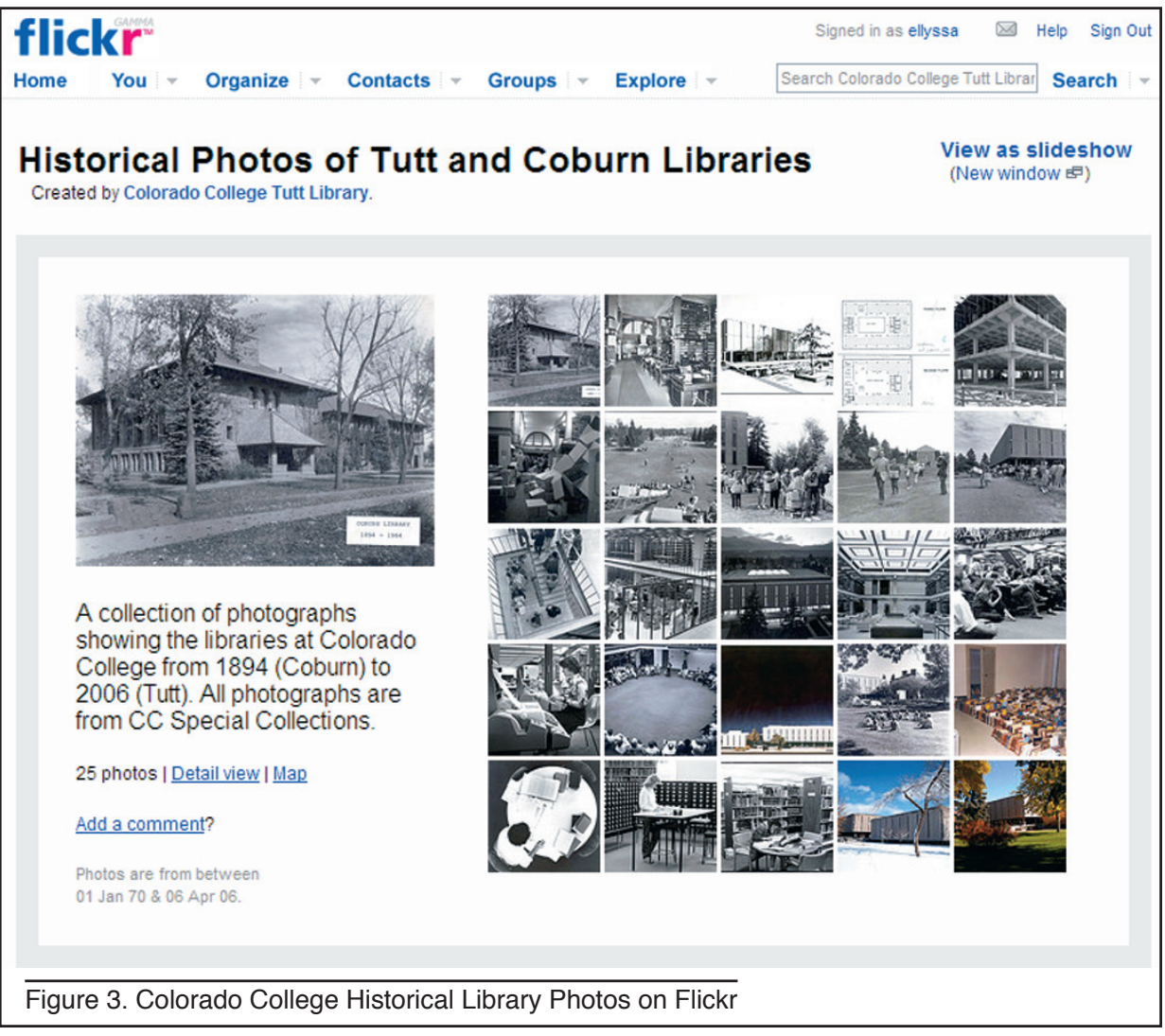

braries dating back to the nineteenth century, and has made it available to the public via Flickr.

\section{Library Tourd}

The reference librarians of Williams College have created a Library Welcome Video for new students, leading them on their way through a Library Mystery Tour. This engaging video on YouTube introduces students to the campus library as well as to its friendly and approachable reference librarians.

\section{Instruction}

Video enables authors to demonstrate tasks in a variety of creative ways, making them powerful tools for teaching. The mechanical engineering librarian at the Georgia Institute of Technology has created GTMechEngVids, a collection of YouTube Webcasts on library research, showing students how to search cited references and patents, and how to find journals.

\section{Marketing}

The American Library Association has mounted ALA photos on Flickr, a collection of hundreds of photos showcasing ALA staff, volunteers, speakers, and attendees at its conferences and events for the past two years. Since photo sharing applications enable creators to exhibit captivating images from programs and events such as these, they serve as ideal marketing vehicles.

\section{Library Staff}

A helpful staff at the Arizona State University Libraries is portrayed in the asulibmarketing's photos taken at its "Lost" event, in which staff assisted 3,700 students in finding their way around campus. Their inviting interactions with new library patrons do much to bolster their image as a welcoming and informative part of the university community. 


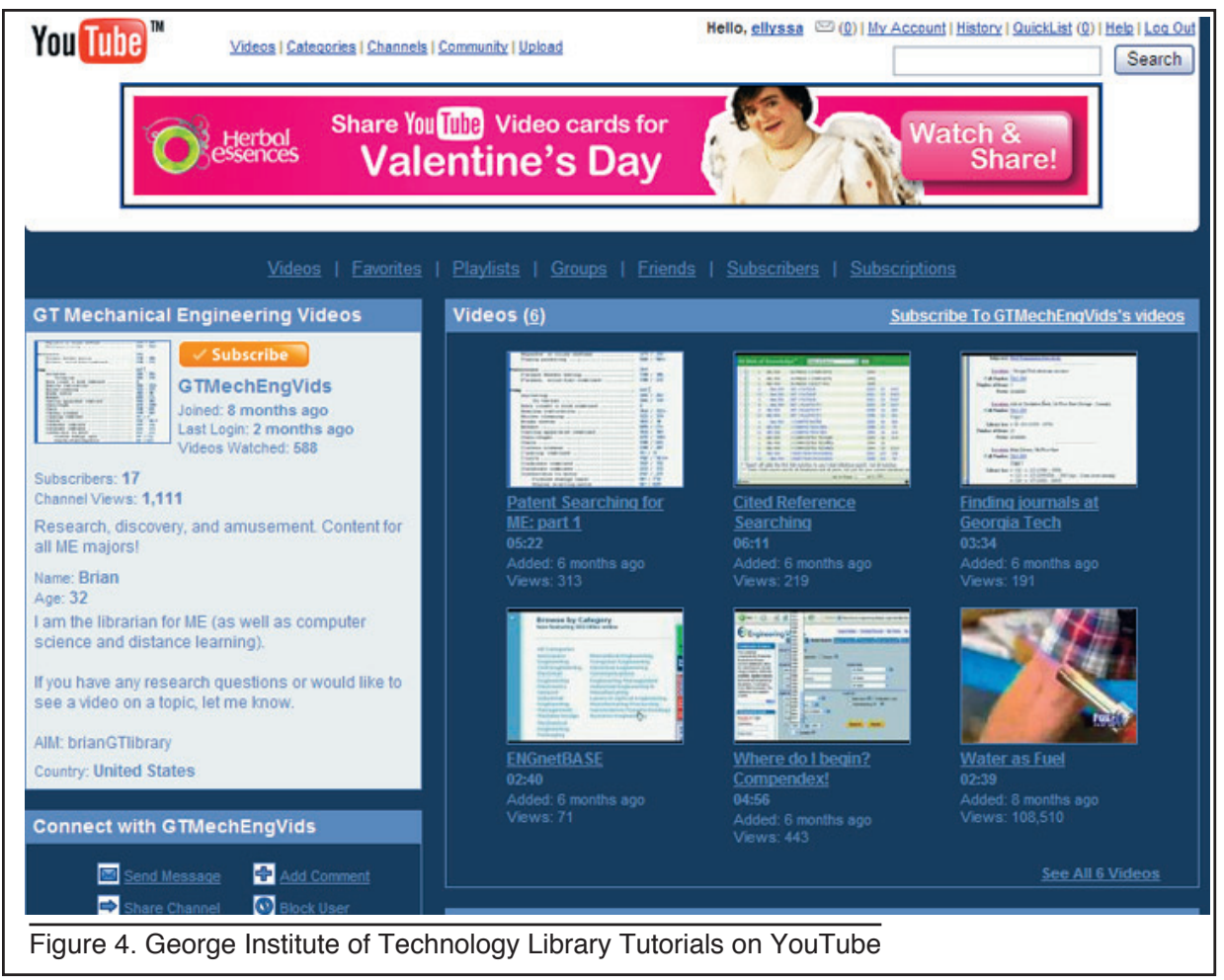

\section{Social Networking}

S ocial networking Web sites are online hubs where people can gather and connect with others in a virtual community. They offer their population a place to establish public identities, or profiles, as well as tools to create and display personal content such as blogs, photos, videos, and audio files. Within community-based Web sites such as MySpace and Facebook, people are swapping stories, imparting wisdom, befriending, mentoring, and learning from one another. They are seeking out and establishing relationships with those who have similar interests, share common goals, or work in the same industry. They are forming thriving ecosystems made up of millions of members who are trading privacy for a sense of belonging and the promise of discovery.

The social networking experience revolves around the user profile. It is the customizable public profile that serves as the starting point for members, as well as the main form of navigation for these sites. Profiles aggregate members' personal content, such as photos, videos, and journal entries, as well as biographical information, interests, ambitions, and character traits that they want shown to the world.

Members of these communities can create their own social networks by building friends lists and by joining groups based on topic or interest area that act as subcommunities within the larger network. The driving force behind such systems is to connect people to people, so the best way to traverse them is by browsing users. There are often advanced search and browse tools provided to assist in the discovery of compatible connections.

\section{Social Networking Web Sites}

Social networking Web sites are available in both general and niche varieties for peo-

\section{Web 1.0 Social Networking}

Web users seeking online community previously gathered around message boards, IRC channels, and AOL chat rooms. These tools allowed limited interaction among small groups based on areas of interest. ple seeking an online community experience. General interest communities such as $M y S$ pace and Bebo have a mainstream audience with a wide range of interests and perspectives, while social Web sites such as LinkedIn (for professionals) and Maya's Mom (for parents) are aimed at niche users.

Purchased by News Corp. in 2005 for $\$ 580$ million, MySpace is the sixth most popular Web site online today and the leading social networking milieu. The community heavyweight boasts over 130 million members -8 million new members sign up each month. Members can listen to hundreds of thousands of music and video files; explore a community of budding comedians, musicians, and filmmakers; and network with, comment on, and join groups of millions of other members.

Facebook is an academic social networking community comprised primarily of students, faculty, and personnel of educational organizations. Since their launch in 2004, they have gained over 16 million members who are able to blog, comment, create friends lists, and join over 47,000 groups or networks within the site. Members enjoy advanced privacy controls that enable them to limit access to information.

Nipping at the heels of MySpace is Google's social networking community orkut, which is the eighth most-trafficked Web site on the Internet, according to Alexa traffic rankings. Over 8 million of its 42 million members reside in Brazil, making it the most popular Web site in the country. This highly visited social domain enables its members to join thousands of groups and create photo galleries, bookmarks, and friends lists.

\section{Web 2.0 Social Networking}

Today's social networking experience takes place within robust communities that allow members to provide detailed profile information and multimedia files. Communities are composed of millions of people seeking to create and connect in the same public sphere. 
LinkedIn is a professional social networking community geared toward people seeking to make business connections. Over 8.5 million people have created resumes within the community, in which members can seek recommendations from contacts, post job openings, search for jobs, and create business networks.

\section{Social Networking and Academic Libraries}

Libraries are utilizing social networking communities as marketing platforms, tools for outreach, and networking venues. Due to their enormous popularity with the general public, they offer libraries a unique opportunity to interact with patrons in their own space.

\section{Library Portals}

The UIUC Undergrad Library has established a MySpace page which acts as a portal leading back to the University of Illinois at Urbana-Champaign library Web site. They have even created a library catalog search box that other MySpace members can add to their profiles. By building a presence within an online community where many of their patrons currently interact, the library becomes more accessible and highly visible to a large demographic of potential users.

\section{Promotion}

Social networking Web sites allow people to feature detailed descriptive information along with photos, videos, and audio files within their profiles, making them customizable marketing vehicles. The library at the University of Central Florida is utilizing its page within the MySpace community to connect with millions of other members to promote the UCF Ask a Librarian service and spotlight library resources.

\section{Networking}

Since these social Web site communities are all about creating relationships between members, they offer infinite networking opportunities. The American

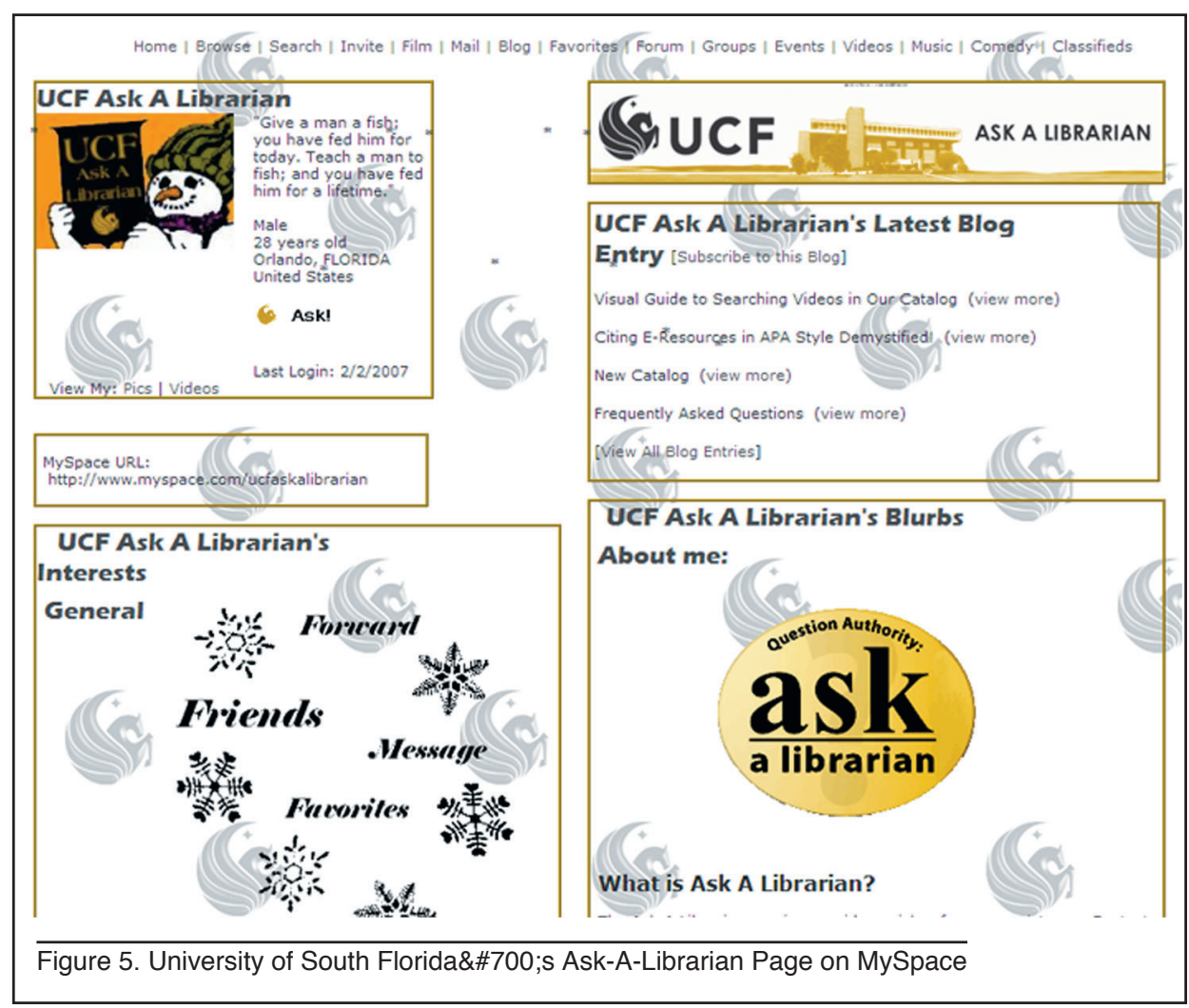

Library Association has established a presence within MySpace that has acquired over 450 connections in its friends list.

\section{Outreach}

Many librarians have joined the 16 million members of the Facebook community to offer their services. They are blogging, joining groups, and creating detailed profiles inviting students, faculty, and staff of the educational community to call on them for research assistance.

\section{Conclusion}

The social tools of Web 2.0 offer libraries a great many opportunities to interact with their patrons and each other. These new Web applications provide the means to quickly and easily create valuable resources, discover new ones, collaborate, keep current, build relationships, and promote programs. Through these new social applications, libraries are able to go where their users are in order to create, contribute, and connect to a global community.

\section{Notes}

1 Oldenburg, Ray. The Great Good Place: Cafés, Coffee Shops, Bookstores, Bars, Hair Salons, and Other Hangouts at the Heart of a Community. New York: Marlowe, 1999.

2 Cohen, Laura B. "Blogs in Academia: A Resource Guide," Choice, v.43, August 2006. 


\section{Links Cited}

\section{Content Collaboration}

Antioch University New England Library Staff Training and Support Wiki

Antioch University New England

http://www.seedwiki.com/wiki/antioch_university_new_ england_library_staff_training_and_support_wiki/

or http://tinyurl.com/28672j/

Biz Wiki

Ohio University Libraries

http://www.library.ohiou.edu/subjects/bizwiki/

Google Docs é Spreadsheets

Google

http://docs.google.com/

JotSpot

Google

http://www.jotspot.com/

libadvisorywiki

Mesquite ISD Library Advisory Committee

http://libadvisorywiki.pbwiki.com/

\section{MediaWiki}

MediaWiki.org

http://www.mediawiki.org/

Official Wiki of the 2007 ALA Anmual Conference in Washington, DC

American Library Association

http://wikis.ala.org/annual2007/

PBWiki

PBwiki, Inc.

http://pbwiki.com/

Socialtext Enterprise Wiki

Socialtext Incorporated

http://www.socialtext.com/

ThinkFree Online Office

ThinkFree, Corp.

http://www.thinkfree.com/

University of Connecticut Libraries' Staff Wiki

University of Connecticut Libraries

http://wiki.lib.uconn.edu/wiki/
USC Aiken Gregg-Graniteville Library

University of South Carolina - Aiken

http://library.usca.edu/

Wikipedia: The Free Encyclopedia (CH, Mar'06, 43-3736)

Wikimedia Foundation

http://www.wikipedia.org/

\section{Zobo Office Suite}

AdventNet, Inc.

http://www.zoho.com/

\section{Social Bookmarking}

ala2007 (Pages tagged with "ala2007" on del.icio.us)

http://del.icio.us/tag/ala2007/

\section{CiteULike}

Richard Cameron

http://www.citeulike.org/

\section{Connotea}

Nature Publishing Group

http://www.connotea.org/

del.icio.us

Yahoo! Inc.

http://del.icio.us/

il2006 (Pages tagged with "il2006" on del.icio.us)

http://del.icio.us/tag/il2006/

library (Pages tagged with "library" on del.icio.us)

http://del.icio.us/tag/library/

library2.0 (Pages tagged with "lbrary2.0" on del.icio.us) http://del.icio.us/tag/library2.0/

lis753 (Pages tagged with "lis753" on del.icio.us)

Michael Stephens, Dominican University Reading List http://del.icio.us/tag/lis753/

PennTags

http://tags.library.upenn.edu/

SanMateoLibrary's Bookmarks on del.icio.us

http://del.icio.us/SanMateoLibrary/

StumbleUpon

StumbleUpon

http://www.stumbleupon.com/ 


\section{Media Sharing}

ALA photos on Flickr

American Library Association

http://www.flickr.com/photos/ala_members/

asulibmarketing's photos

Arizona State University Libraries

http://www.flickr.com/photos/asulibraries/

Flickr

Yahoo! Inc.

http://www.flickr.com/

GTMechEngVids

Georgia Institute of Technology YouTube Videos

http://www.youtube.com/profile? user=GTMechEngVids /

or http://tinyurl.com/38zt2g/

Historical Photos of Tutt and Coburn Libraries

Colorado College

http://www.flickr.com/photos/tuttlibrary/sets/7205759409

7880019/

or http://tinyurl.com/3bx3wr/

Library Welcome Video

Williams College

http://www.youtube.com/watch?v=i-t0LHnw-fc/

or http://tinyurl.com/2ltmx2/

Metacafe

Metacafe, Inc.

http://www.metacafe.com/

Photobucket

Photobucket, Inc

http://photobucket.com/

Yahoo! Video

Yahoo! Inc.

http://video.yahoo.com/

YouTube

YouTube, Inc.

http://www.youtube.com/

\section{Social Networking}

American Library Association (on MySpace)

http://www.myspace.com/atyourlibrary/
Bebo

Bebo, Inc.

http://www.bebo.com/

Facebook

Facebook, Inc.

http://www.facebook.com/

LinkedIn

LinkedIn Corporation

http://www.linkedin.com/

Maya's Mom

Maya's Mom, Inc.

http://www.mayasmom.com/

MySpace

MySpace.com

http://www.myspace.com/

orkut

orkut.com LLC and Google

http://www.orkut.com/

UCF Ask a Librarian (on MySpace)

University of Central Florida Library

http://www.myspace.com/ucfaskalibrarian

UIUC Undergrad Library (on MySpace)

University of Illinois at Urbana-Champaign Undergraduate Library

http://www.myspace.com/undergradlibrary/ 